\title{
How to make your child safe in viral pandemic
}

\author{
Juhi Dutta ${ }^{1}$, Arnab Nandy ${ }^{2}$, Rakesh Mondal ${ }^{3}$ \\ From ${ }^{1}$ Resident, Department of Pediatrics, Institute of Child Health, Kolkata, ${ }^{2}$ Resident, Department of Pediatrics, North Bengal Medical College and \\ Hospital, Darjeeling, ${ }^{3}$ Professor, Department of Pediatrics, Medical College and Hospital, Kolkata, West Bengal, India
}

\begin{abstract}
The current coronavirus $(\mathrm{CoV})$ disease-19 pandemic has taken the entire world to hell and back. While we are more focused on the containment of this virus from further spreading, there are certain imperceptible challenges which are gradually raging upfront to affect the overall child health. If they are not understood appropriately overtime, it can result into deleterious sequels in near future. The tangible effects of this viral pandemic also deserve similar attention alongside exploring the pathophysiology of medical illnesses caused by severe acute respiratory syndrome-CoV-2. A practical approach to address these issues has been discussed here considering "the new normal" as the future lifestyle.
\end{abstract}

Key words: Adaptive behavior, Child health, Coronavirus disease-19, Pandemic, Parenting

$\mathrm{T}$ he recent outbreak of the novel coronavirus $(\mathrm{CoV})$ (severe acute respiratory syndrome-CoV [SARS-CoV-2]) infection has compelled the agile world to come into standstill. The human race which is galloping with the dream to vanquish all its' malady has become bewildered instantaneously by the catastrophe. The ghastly CoV disease (COVID)-19 pandemic has taken its' toll on almost every human being by affecting both their mental and physical health. Yet, the invincible spirit lies within us has been the cornerstone throughout the time to fight against this invisible foe [1]. While we are gradually learning "The new normal," certain tangible effects of this viral pandemic are evident on child health $[2,3]$. It is desirable for the parents to get acquainted with these unspoken perils beforehand. Awareness about these puzzles can prevent child's pain and allow the parents to adopt a pandemic appropriate behavior for their children.

\section{STAYING INDOOR}

"Stay home and Stay safe" is the principle, which is accepted universally. While staying indoor, certain issues must be taken care of like keeping the living space well ventilated and clean, and maintenance of quality hygiene. The practice of using hand sanitizer at the point of entering the house from outside should be followed by every person. It is advisable to make arrangement of a separate space or room for the members of the house to get clean and tidy

\section{Access this article online}

Received - 18 September 2020

Initial Review - 03 October 2020

Accepted - 17 October 2020

DOI: $10.32677 / \mathrm{IJCH} .2020 . v 07.110 .001$ when they return from outside. Keeping the face mask at a clean and dry place beyond the reach of a child in the house is important. Parents should help their children to get gradually familiar with the use of face mask. Children should be tenderly introduced to the importance of good hygiene maintenance and they must be encouraged to practice it in daily life. Parents should also teach their children about the necessity of maintaining physical and social distance. Children should be encouraged to wash their hands with soap and water, before touching their face. For most of the domestic face masks available, cumulative use of more than $24-48 \mathrm{~h}$ is not advisable. The reusable ones must be washed on a regular basis. It is recommended to refrain from visiting crowded or closed spaces with poor ventilation, relatives, or neighbors, unless it is unavoidable.

\section{RISE IN SCREEN TIME}

Too much screen time on electronic gadgets drain mind and body along with the development of certain maladaptive behaviors such as online gambling and conduct disorders [4]. Screen time should not be more than 1-1.5 h a day (excluding online classes). It is better to spent time with your child by telling them good stories and encouraging them to read books. Parents should have a schedule of interactive play session with their child in day-to-day routine. Engaging your child in the home activities is also a good alternative. Teaching and involving your little ones into the practice of different extracurricular activities such as singing, recitation, and playing instruments are much appreciated. Unrestricted and unmonitored use of the electronic gadgets or leaving the children

Correspondence to: Dr. Arnab Nandy, Department of Pediatrics, North Bengal Medical College, Darjeeling, West Bengal, India. E-mail: arnabn.office@gmail.com

(C) 2020 Creative Commons Attribution-NonCommercial 4.0 International License (CC BY-NC-ND 4.0). 
on their own while the parents are being relentlessly engaged in their office or routine works is not desirable.

\section{VIRTUAL CLASSROOM}

Virtual platform has emerged as the working medium for teaching. Basic introduction to the electronic gadgets is required for the participation in online teaching program. None should be shy to ask for expert help. Frequent washing of the face with running tap water is desired. Parents should encourage their children to actively participate in the online class discussion along with taking notes. Online group discussions need to be appreciated. One must keep in mind that excessive indulgence into the Socratic or one-way method of communication can be harmful. Consecutive sessions of virtual interactions, without intermediate breaks should be avoided.

\section{SEDENTARY HABITS, PSYCHOSOCIAL DEVELOPMENT, AND HOME ATMOSPHERE}

It is evident that weeks and months of staying at home can have adverse effects on the health. Free hand exercises in divided sessions can be very helpful in this regard. Simple lessons of yoga are also advisable. Parents should engage their kids along with themselves with these activities [5]. It will help to get the maximum reinforcement. Pay attention to your child's thoughts and encourage them to choose what is right. Parents and other family members who are staying under the same roof should spend time and help the child in completing his/her home tasks. Parents must be concerned about the temper tantrums of their children and if necessary, they can even seek for expert advice. It is better to avoid reverberating melancholic and negative thoughts in front of your child. Parents should refrain from having a relentlessly frightful home environment by discussing gloom-ridden facts only. It is important to be aware of your own mood swings which can affect the child adversely.

\section{AUXILIARY PLAY SCHEDULE}

Play has an important role for socioadaptive and cognitive development of a child [6]. Age appropriate toys such as multiball set, stacking and sorting blocks, and sticker books are handful to keep the pre-school child engaged. Parents can introduce the child to play different musical instruments or even gardening and solving puzzles. In an enclosed playroom, a small group of children can be allowed for onlooker play, under the guidance of their parents. If the child has sibling, parents shall encourage parallel play in between them where one learns how to relate to others. It is desirable for the parents to actively participate in these cooperative plays. Parents are advised to interact with their children in a limpid manner to express their keenness to play. It is not advisable for the parents to be directive all the time while a child explores himself/herself through play. Freedom of play must not be affected by the dominion of peer pressure or undue insistence on study.

\section{FEEDING BEHAVIORS}

The never-ending search of the parents for a balanced diet for their children has become more difficult due to a compromised chain of raw material supply. Fresh fruits and vegetables which are rich source of Vitamins A, D, and E, alongside plenty of antioxidants and trace elements such as zinc and copper are known to enhance immunity [2]. Four major meals with in-between snacks are usually sufficient for the school-aged children. Rotation of various food items is desirable. Parents can try newer recipe with the common groceries available at home which will serve the purpose of taste changing for their children. Parents should focus on finding positive reinforcements for their children to finish off their meal more eagerly. Fresh vegetables are always welcome. Monotonous cooking recipes will keep children away from their meal. Excessive intake of oily and junk foods should be avoided. Raw materials of cooking which are stored for long period of time shall be inspected from time to time and must be discarded at the first visible site of rotting.

\section{CHILD IMMUNIZATION AND CHRONIC AILMENTS}

The current situations are perplexing for the parents to cope with these essential health issues. Parents are advised to adhere to the Routine Immunization Schedule of their children [7]. They must follow COVID-19 infection prevention guidelines and the other mitigation measures, during the immunization sessions. Vaccination of the newborns in maternity hospitals and primary series of vaccination for polio, hepatitis B, diphtheria, pertussis, tetanus, measles-rubella, and other combinations should be prioritized. Infected and quarantined mothers are advised to get their children vaccinated in consultation with the treating physician. Parents can also look for the availability of "drop in vaccination" facility provided by the public or private institution nearest to them.

Parents or the guardians should ask the treating physician about the latest guidelines for interrupted or delayed routine immunizations which are issued by the World Health Organization and the leading bodies of the country. Information is also available at iap.org.in. Monitoring of the acute exacerbation of chronic illnesses is important. It is advised to have adequate stock of emergency and essential medicines at home which are required for the management chronic ailments. Parents should not get frightened with temporary disruption of immunization schedule or with the unavailability of vaccines as subsequent vaccine doses do have a permissible window to vaccinate. It is recommended not to be shy of seeking medical advice from the physician over telephone or emergency medical helpline numbers provided by the government.

\section{SOCIAL OBLIGATION TO PREVENT COMMUNITY SPREAD}

In view of the recent perspective, the primary goal has been set to control this viral pandemic by preventing the spread of infection 
by adopting the measures such as maintenance of hand hygiene, wearing face masks in public spaces, social distancing, and self or institutional quarantine [8]. The SARS-CoV-2 virus is observed to spread from person to person through respiratory droplets and these are produced while an infected person coughs, sneezes, or talks. To prevent spread of the droplets to the nearby people, it is advised to cough or sneeze into the elbow or cover the mouth and nose while doing so [3,9]. Frequent hand washing, avoiding close contacts, and daily health monitoring for fever, respiratory symptoms, and blood oxygen saturation with pulse oximeter are very helpful. High-touch areas such as door handles and bedside tables should be disinfected routinely with available household disinfectant to aid in decreasing secondary cases. Fogging with disinfectants in the places with higher probability of overcrowding should be done at regular intervals. Significant proportion of the population affected by this viral infection is observed to be asymptomatic or having mild symptoms [10]. Thus, it must be the responsibility of the entire society to follow all the mitigation measures as mentioned above, to make the environment safer for the patients with chronic ailments and others also. It is evident that social awareness and promotion of health education are ought to be the key in this regard.

\section{REFERENCES}

1. Halperin DT. Coping With COVID-19: Learning from past pandemics to avoid pitfalls and panic. Glob Health Sci Pract 2020;8:155-65.

2. Akseer N, Kandru G, Keats EC, Bhutta ZA. COVID-19 pandemic and mitigation strategies: Implications for maternal and child health and nutrition. Am J Clin Nutr 2020;112:251-6.

3. World Health Organisation. Local Epidemiology Should Guide Focused Action in 'New Normal' COVID-19 World. New Delhi: SEARO; 2020. Available from: https:/www.who.int/southeastasia/news/detail/15-05-2020local-epidemiology-should-guide-focused-action-in-new-normal-covid-19world. [Last accessed on $2020 \mathrm{Jul} 25]$.

4. Pearson N, Biddle SJ, Griffiths P, Sherar LB, McGeorge S, Haycraft E. Reducing screen-time and unhealthy snacking in 9-11 year old children: The kids FIRST pilot randomised controlled trial. BMC Public Health 2020;20:122.

5. Downing KL, Hnatiuk JA, Hinkley T, Salmon J, Hesketh KD. Interventions to reduce sedentary behaviour in 0-5-year-olds: A systematic review and metaanalysis of randomised controlled trials. Br J Sports Med 2018;52:314-21.

6. Ginsburg KR. The importance of play in promoting healthy child development and maintaining strong parent-child bonds. Pediatrics 2007;119:182-91.

7. Abbas K, Procter SR, van Zandvoort K, Clark A, Funk S, Mengistu T, et al. Routine childhood immunisation during the COVID-19 pandemic in Africa: A benefit-risk analysis of health benefits versus excess risk of SARS-CoV-2 infection. Lancet Glob Health 2020;8:e1264-72.

8. Güner R, Hasanoğlu I, Aktaş F. COVID-19: Prevention and control measures in community. Turk J Med Sci 2020;50:571-7.

9. Nicola M, O’Neill N, Sohrabi C, Khan M, Agha M, Agha R. Evidence based management guideline for the COVID-19 pandemic-review article. Int $\mathrm{J}$ Surg 2020;77:206-16.

10. Banerjee S, Guha A, Das A, Nandy M, Mondal R. A preliminary report of COVID-19 in children in India. Indian Pediatr 2020;57:963-4.

Funding: None; Conflicts of Interest: None Stated.

How to cite this article: Dutta J, Nandy A, Mondal R. How to make your child safe in viral pandemic. Indian J Child Health. 2020; 7(10):401-403. 